\title{
NATURAL CONVECTIVE HEAT TRANSFER IN A POROUS MEDIUM WITHIN A TWO DIMENSIONAL ENCLOSURE
}

\author{
MEHDi AHMADI \\ Department of Mechanical Engineering, Islamic Azad University, \\ Shahrekord Branch, Ardal Center, Iran. \\ Corresponding author:ahmadi.m@iaushk.ac.ir \\ (Received: 26 ${ }^{\text {th }}$ Oct. 2015; Accepted: $30^{\text {th }}$ Nov. 2017; Published on-line: $1^{\text {st }}$ Dec. 2017)
}

\begin{abstract}
In the present paper, the effect of heating sources on the rate of heat transfer is studied by increasing the number of heat sources. The number of heat sources is increased at every stage in a way that the space occupied by them remains constant. The finite-volume method has been used to solve the continuity, Navier-Stokes, and energy equations. Then, by calculating the amount of heat transfer in different Rayleigh numbers, it was found that minifying and distributing solid phase heating in the enclosure increased the total Nusselt number and the heat transfer. One factor could be the increased severity of fluid motion in the corners and near the walls of the enclosure. In next stage, by placing the solid components in the enclosure, the porous model can be created. As the results indicate, by increasing the average Rayleigh number, the Nusselt number increased. Also, with an increase in the Darcy number, the heat transfer rate dropped in the porous medium. Considering that a large share of heat transfer in porous media is performed by conduction, increased permeability increases heat transfer; thus has a negative impact on directed heat transfer and thus the entire heat transfer.
\end{abstract}

ABSTRAK: Kertas kajian ini mengkaji tentang kesan peningkatan kadar bilangan sumber kepanasan haba ke atas pemindahan haba. Bilangan sumber kepanasan haba di tambah pada setiap tingkatan dengan cara menetapkan luas litupan permukaan secara konsisten. Kaedah Finite-volume telah diguna pakai untuk menyelesaikan masalah pengkadaran, kaedah Navier-Stokes dan formula persamaan tenaga. Seterusnya, kadar pengiraan total pemindahan haba mengguna nombor Rayleigh yang berbeza, telah mendapati penimimuman dan penularan kepanasan pada fasa pepejal dalam bekas tertutup telah meningkat pada total nombor Nusselt dan pada pemindahan haba. Salah satu faktor mungkin disebabkan oleh peningkatan maksima pada pergerakan cecair di sudut-sudut dan berhampiran dinding bekas tertutup. Seterusnya, dengan meletakkan komponen pepejal dalam bekas tertutup, model porus dapat dicipta. Keputusan menunjukkan, nombor Nusselt bertambah dengan kadar peningkatan nombor Rayleigh. Disamping itu, kadar pemindahan haba turut menurun dalam medium porus dengan peningkatan nombor Darcy. Pada keseluruhannya, pemindahan haba dalam medium porus telah dijalankan dengan kaedah pemindahan tenaga, dengan peningkatan kadar resapan, pemindahan haba turut bertambah. Seterusnya memberi kesan negatif pada kadar secara langsung dan pada keseluruhan pemindahan haba.

KEYWORDS: heat transfer; natural convection; porous media; enclosure; heating sources

\section{INTRODUCTION}

Heat transfer and flow convection, forced and combined for numerous applications in the industry are widely studied by researchers. Heat exchangers, storage of minerals, 
spread of pollutants and groundwater levels, environmental controls, bean and grain storage, food production and food processing, construction materials and metals processing, advanced heating systems, oil, warehousing and storage of nuclear waste, solar collectors, design of furnaces, crystal growth in liquid security in nuclear reactors are only examples of applications of the subject for study. In addition, natural convection plays an important role in porous models, which are frequently used in engineering and environmental sciences. Many researchers have studied natural convection within the enclosure with different dimensions and different forms, and also referred repeatedly to mixed convection. In this paper, natural convection within the enclosure with heat sources or solid phase is more considered.

Recently, the special boundary condition was considered in a rectangular enclosure by Alam et al. [1]. Deng [2] numerically investigated the effects of the aspect ratio, location and arrangement of multiple discrete sources mounted on the vertical sidewalls. They found that the total heat transfer was closely related to the number of eddies in the enclosure. The determination of the critical Rayleigh number and the frequency of oscillatory flow has been found in the works of Ghernaout et al. [3] who studied the effect of the buoyancy ratio on the oscillatory double-diffusive convection in binary mixture, and in [4], investigated the effect of an external magnetic field on the 3D oscillatory natural convection during phase change. A steady laminar natural convection in $2 \mathrm{D}$ enclosures heated from below and cooled from above for a wide variety of thermal boundary conditions at the sidewalls has been carried numerically by Corcione [5]. An analysis on the combined effects of thermal and mass diffusion of viscous incompressible fluid through a finitely long vertical irregular wall and a smooth flat wall in the presence of an internal heat source or sink was performed by Fasogbon [6]. In his study, walls were maintained at constant but different temperatures and species concentrations. An experimental and numerical study of free convective heat transfer in a square enclosure characterized by a discrete heating at lower wall and cooled from the vertical walls have been analyzed by Calgagni et al. [7]. A numerical investigation of natural convection of air in a vertical square cavity with localized isothermal heating from below and symmetrical cooling from the side walls was investigated by Aydin and Yang [8].

Such research in this area can be noted heat transfer of natural convection from a square solid block in the center of an enclosure [9], heat transfer of fluid within an enclosure with the solid parts of energy producer $[10,11]$ and also cooling of wire ring within the enclosure by natural convection flow. Sezai and Mohamad [12] studied natural convection from a discrete heat source on the bottom of a three-dimensional horizontal enclosure. The local Nusselt number for different Rayleigh number and sizes was drawn through the enclosure. Merrikh and Lage [13] studied heat transfer from the walls in front of a two-dimensional enclosure with solid blocks between walls. Natural convection in the fluids within the enclosure, which included a large part of the solid phase, can be a model of porous bodies that make an important issue with many applications in engineering sciences and environmental issues. According to the importance of this issue, much research has been done in this field. Among this research, a paper by Braga and Lemos [14] should be noted. They studied heat transfer from surfaces facing each other (hot and cold) in a square enclosure located with conductive solid blocks with square and circle sections. Researchers in another study [15], studied the rate of heat transfer of natural convection (laminar and turbulence) from the walls of the enclosure when there were parts of the solid phase within. Two methods were suggested and the results were compared. In this method parts of the solid phase were in the form of squares, uniformly placed in the enclosure. Following the studies of these researchers, in the present paper seeks to assess 
the effect of heating components on the rate of heat transfer. The effect of increased heating components on the heat transfer rate will be reviewed, an aspect that is less noticed by the other researchers. Therefore, in each stage, the number of heating components is increased but the space they occupied remained constant. Then, to get the desired results, the amount of heat transfer was calculated (average Nusselt of enclosure walls) in different Rayleigh numbers. As mentioned earlier, some researchers [14, 15] have investigated an approximate model to calculate the heat transfer of porous media. The current paper used the model suggested by these researchers. For this purpose, the boundary conditions of the enclosure are changed when the horizontal walls are insulated and vertical walls are considered at different temperatures, by putting the conductive pieces within the enclosure. For an average Rayleigh number, results (with different numbers of solid blocks) are compared with the present results for a porous media.

\section{MODELLING AND SIMULATION}

\subsection{Mathematical Model}

The fluid flow considered here is the air $(P r=0.71)$ and it is assumed to be Newtonian, incompressible, steady state, except that the Boussinesq approximation is valid. The enclosure is characterized by heat sources that increase from $N=1$ to $N=256$ that are symmetrically placed on the enclosure. Each heat source is maintained at hot temperature $T_{h}$, and characterized by a height and a length $D$, and enclosure dimensions are $H$, (as shown in Fig.1).

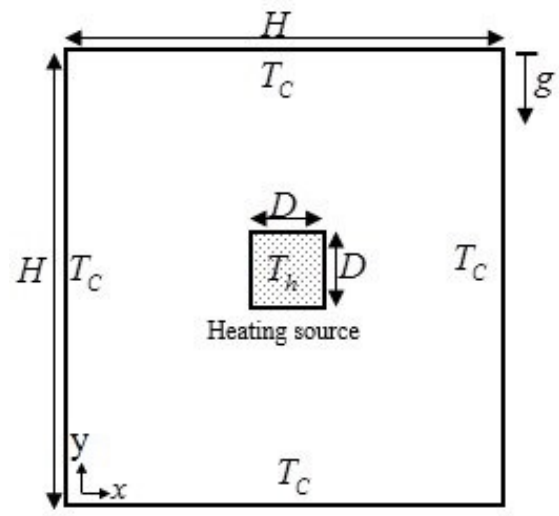

Fig. 1: The image of an enclosure with heat source in the center.

The dimensionless equations governing continuity, Navier-Stokes, and energy can be expressed as follows [16]:

$\frac{\partial U}{\partial X}+\frac{\partial V}{\partial Y}=0$

$\frac{\partial U}{\partial \tau}+U \frac{\partial U}{\partial X}+V \frac{\partial U}{\partial Y}=-\frac{\partial P}{\partial X}+\left(\frac{\partial^{2} U}{\partial X^{2}}+\frac{\partial^{2} U}{\partial Y^{2}}\right)$

$\frac{\partial V}{\partial \tau}+U \frac{\partial V}{\partial X}+V \frac{\partial V}{\partial Y}=-\frac{\partial P}{\partial Y}+\left(\frac{\partial^{2} V}{\partial X^{2}}+\frac{\partial^{2} V}{\partial Y^{2}}\right)+G r \theta$ 


$$
\frac{\partial \theta}{\partial \tau}+U \frac{\partial \theta}{\partial X}+V \frac{\partial \theta}{\partial Y}=\frac{1}{\operatorname{Pr}}\left(\frac{\partial^{2} \theta}{\partial X^{2}}+\frac{\partial^{2} \theta}{\partial Y^{2}}\right)
$$

The dimensionless variables used to create the governing equations, Eqs. (1)-(4), are defined as:

$X=\frac{x}{H}, Y=\frac{y}{H}, U=\frac{u}{u_{C}}, V=\frac{v}{v_{C}}, P=\frac{p}{u_{C}^{2}}, \theta=\frac{T-T_{C}}{T_{h}-T_{C}}$

$u_{C}=\left(g \beta\left(T_{h}-T_{C}\right) H\right)^{1 / 2}, G r=\frac{g \beta\left(T_{h}-T_{C}\right) H^{3}}{v^{2}}, \operatorname{Pr}=\frac{v}{\alpha}$

With the boundary conditions, on the walls:

$U=V=0$

On the surface of hot and cold sources:

$\theta=1, \theta=0$

And for adiabatic walls:

$$
\left.\frac{\partial \theta}{\partial X}\right|_{X=0}=0,\left.\frac{\partial \theta}{\partial Y}\right|_{Y=0}=0
$$

Where $X, Y$ are dimensionless coordinates along horizontal and vertical directions, respectively, $U, V$ are dimensionless velocity components in the $\mathrm{x}-\mathrm{y}$ directions, respectively, $\theta$ is the dimensionless temperature, $P$ is the dimensionless pressure.

\subsubsection{Porous media equations}

There are different methods for heat transfer between two vertical surfaces in porous media. According to the dimensions and conditions of the present paper, the mechanism in which natural convection is dominant than conductive is used. To compute rate of heat transfer in these conditions there are different experimental relations which are mentioned in [17]. Due to this article the porous medium equations are not directly solved and aim is modeling this medium with natural convection relation. The porosity of a porous body which is shown with $\Phi$, is defined as follows:

$\Phi=$ (volume of empty spaces interconnected)/(total volume of porous body)

Permeability of a porous media depends on the porosity and with different relationships can be calculated. In this paper used the following experimental relation [15]:

$K=\frac{D^{2} \Phi^{3}}{120(1-\Phi)^{2}}$

$R a_{m}=R a D a$

$R a=G r \operatorname{Pr}=\frac{g \beta H^{3} \Delta T}{\alpha v}$

$D a=\frac{K}{H^{2}}$

Considering the need to high accuracy of solutions and also high variability in some parameters particularly at solid-fluid boundaries, the non-uniform grid has been used to run the provided program.

\subsection{Solution Procedure}


The governing equations, (1)-(4), are discretized by the finite volume method (FVM) on a non-uniform grid system. The third-order QUICK scheme and the second-order central difference scheme are, respectively, implemented for the convection and diffusion terms. The set of discretized equations for each variable are solved by a line-by-line procedure and the tri-diagonal matrix algorithm (TDMA) is combined with the successive over-relaxation iteration method (SOR). Coupling between velocity and pressure is solved by SIMPLE algorithm. The solution is terminated until the convergence criterion is reached; the maximal residual of all governing equations is less than $10^{-8}$.

\subsection{Validation}

To investigate the performance of the computer code, a comparison was made with other works that will be explained here.

\subsubsection{Natural convection in square enclosure}

The square enclosure is considered with insulated horizontal walls and vertical walls are at two different temperatures, as shown in Fig.2, without a conductive solid block in the center.To use the computer code, the average Nusselt of hot walls for $R a=10^{4}, 10^{5}, 10^{6}$ and $P r=0.71$ calculated in Table 1 . As can be seen, the results are compared with the results of the references are not much different. The differences between present result and references are maximum $0.85 \%$ and average $0.27 \%$, which are negligible.

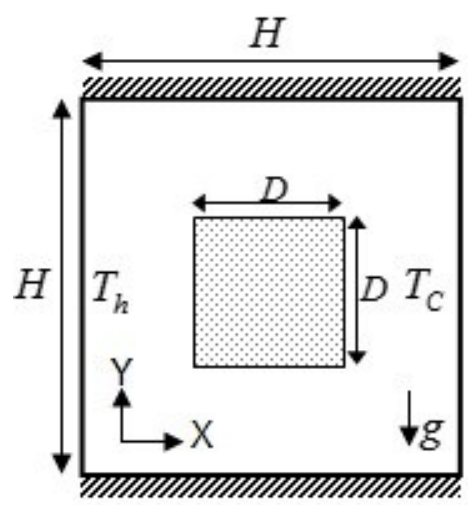

Fig. 2: The square enclosure with insulated horizontal walls and vertical walls at two different temperatures with a solid block in center.

Table 1: Comparison of average Nusselt in square enclosure with the others results.

\begin{tabular}{cccc}
\hline $\boldsymbol{R} \boldsymbol{a}$ & $10^{4}$ & $10^{5}$ & $10^{6}$ \\
\hline De Vahl Davis [18] & 2.243 & 4.519 & 8.800 \\
House et al. [19] & 2.254 & 4.561 & 8.932 \\
Kalita et al. [20] & 2.245 & 4.522 & 8.829 \\
Merrikh and Lage [21] & 2.244 & 4.536 & 8.860 \\
Present results & 2.244 & 4.522 & 8.818 \\
\hline
\end{tabular}

\subsubsection{Enclosure with a Conductive Solid Block in Center}

In this step, the enclosure in previous section is considered with a conductive solid block in center (Fig. 2). Aspect ratio of solid block to enclosure height is as $D / H=0.5$. If the fluid conduction coefficient within the enclosure and the solid block be shown as $k_{f}$ and $k_{s}$, then used the prepared program code and the average Nusselt of hot walls in the 
presence of a solid block were calculated for $\operatorname{Pr}=0.71, R a=10^{5}$ and $k_{s} / k_{f}=0.2$ and 0.5 . The obtained results could be compared in Table 2 with similar cases of mention references. Here, the maximum difference between present results and those of others is too insignificant and negligible. After assurance from program operation, first a suitable grid with regard to boundary conditions was described.

Table 2: The comparison of mean Nusselt in the enclosure with a conducting solid part in the center with those of others $\left(\operatorname{Pr}=0.71, R a=10^{5}\right)$.

\begin{tabular}{cccccc}
\hline $\boldsymbol{R} \boldsymbol{a}$ & $\boldsymbol{D} / \boldsymbol{H}$ & $\boldsymbol{k}_{\boldsymbol{s}} / \boldsymbol{k}_{\boldsymbol{f}}$ & $\begin{array}{c}\text { House et al. } \\
{[19]}\end{array}$ & $\begin{array}{c}\text { Merrikh and } \\
\text { Lage [21] }\end{array}$ & $\begin{array}{c}\text { Present } \\
\text { results }\end{array}$ \\
\hline $10^{5}$ & 0.5 & 0.2 & 4.624 & 4.605 & 4.617 \\
$10^{5}$ & 0.5 & 0.5 & 4.324 & 4.280 & 4.313 \\
\hline
\end{tabular}

\subsection{Grid Study}

Running the prepared computer code and considering the high accuracy of solutions, especially near the solid and fluid phase boundaries that have serious change in some parameters, it is necessary to review the effect of varying the number of grid points on the flow parameters. In this regard, an enclosure with a heating source in the center (Fig. 1) is considered $\left(R a=10^{5}\right.$ and $\left.P r=0.71\right)$. The program was run for different numbers of nodes and the values of average Nusselt of heating source surface and the maximum of stream function $\left(\psi_{\max }\right)$ were obtained.

As can be seen in Table 3, the difference between the values obtained using the $100 * 100$ network and the $110 * 110$ network are very small and are negligible. Thus, nonuniform grid $110 * 110$ are selected to run the program.

Table 3: Maximum values of flow function and mean Nusselt number at all location of hot surfaces for different numbers of nodes in an enclosure with a heating source in the center.

\begin{tabular}{ccc}
\hline Number of nodes & $\begin{array}{c}\text { Average Nusselt of the } \\
\text { hot source surfaces }\end{array}$ & $\boldsymbol{\Psi}_{\max }$ \\
\hline $50 \times 50$ & 5.7214 & 0.2617 \\
$60 \times 60$ & 3.1356 & 0.2620 \\
$70 \times 70$ & 2.0720 & 0.2627 \\
$80 \times 80$ & 2.6980 & 0.2631 \\
$90 \times 90$ & 2.7765 & 0.2633 \\
$100 \times 100$ & 2.8190 & 0.2635 \\
$110 \times 110$ & 2.8235 & 0.2636 \\
$\begin{array}{c}\text { Percentage of the difference } \\
\text { between the values of the grids }\end{array}$ & 0.16 & \\
$100 \times 100$ and $110 \times 110$ & & 0.04 \\
\hline
\end{tabular}

\section{RESULTS AND DISCUSSION}




\subsection{Effect of Increasing the Number of Heating Blocks on the Rate of Heat Transfer}

For this purpose, heating blocks inside the enclosure have been increased from $N=1$ to $N=256$ in a way that the space they occupied and the amount of heat released remained constant. In addition, in all states symmetrical and regular arrangement of blocks in the enclosure has been maintained. The way in which the blocks are located and their dimensions in each case could be observed in Fig. 3. As we observe in this figure, in all cases, the distance between central component and side component from the walls are equal. In each case, total average Nusselt of the enclosure for $R a=10^{3}, 10^{4}, 10^{5}, 10^{6}$ and $P r=0.71$ is calculated and summarized in Table 4. For easier comparison, the results in Table 4 are shown in Fig. 4. Then, by calculating the amount of heat transfer in different Rayleigh numbers, it is clear that minifying and distributing solid phase heating in the enclosure has increased total Nusselt and heat transfer in the whole enclosure, one reason could be high intensity of fluid motion in corners and near the walls of enclosure.

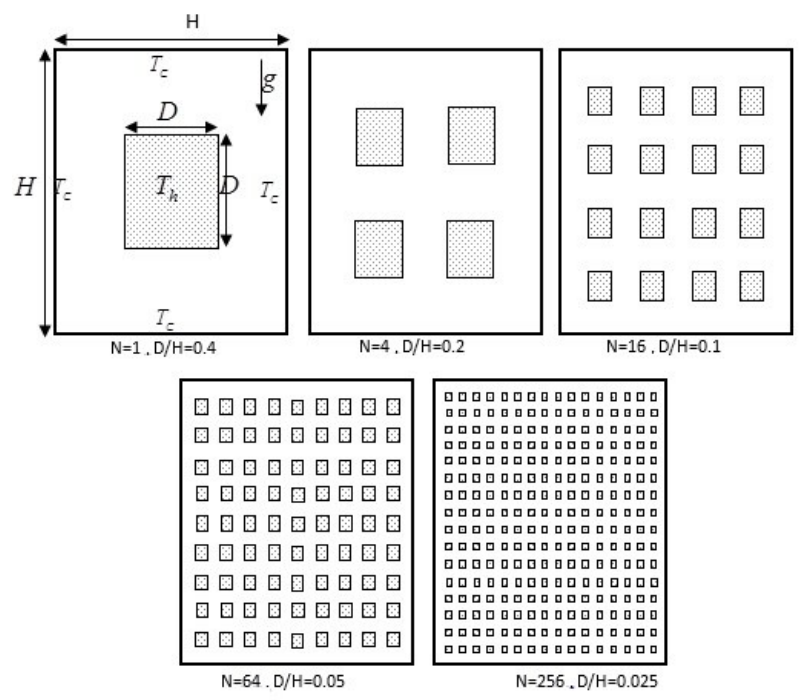

Fig. 3: Different position of enclosure with $N=1,4,16,64,256$ heating blocks.

Table 4: Total average Nusselt of enclosure with different number of heating blocks.

\begin{tabular}{cccccc}
\hline \multirow{2}{*}{$\boldsymbol{N}$} & $\boldsymbol{D}$ & \multicolumn{4}{c}{$\boldsymbol{R} \boldsymbol{a}$} \\
\cline { 3 - 6 } & & $10^{3}$ & $10^{4}$ & $10^{5}$ & $10^{6}$ \\
\hline 1 & 0.400 & 1.893 & 1.906 & 2.814 & 5.405 \\
4 & 0.200 & 3.412 & 3.450 & 4.279 & 7.403 \\
16 & 0.100 & 6.469 & 6.471 & 6.667 & 9.208 \\
64 & 0.050 & 12.645 & 12.645 & 12.652 & 13.144 \\
256 & 0.025 & 25.923 & 25.923 & 25.924 & 25.945 \\
\hline
\end{tabular}

By observing changes in stream lines within the enclosure and by increasing the number of heating components, the rotational flow near the walls can be observed, Fig. 5a. So, a factor in increasing the heat transfer rate influenced by increasing the number of heating components can cause the increase in severity of fluid flow in corners and near the walls of the enclosure, and therefore, increase the natural convection heat transfer. 


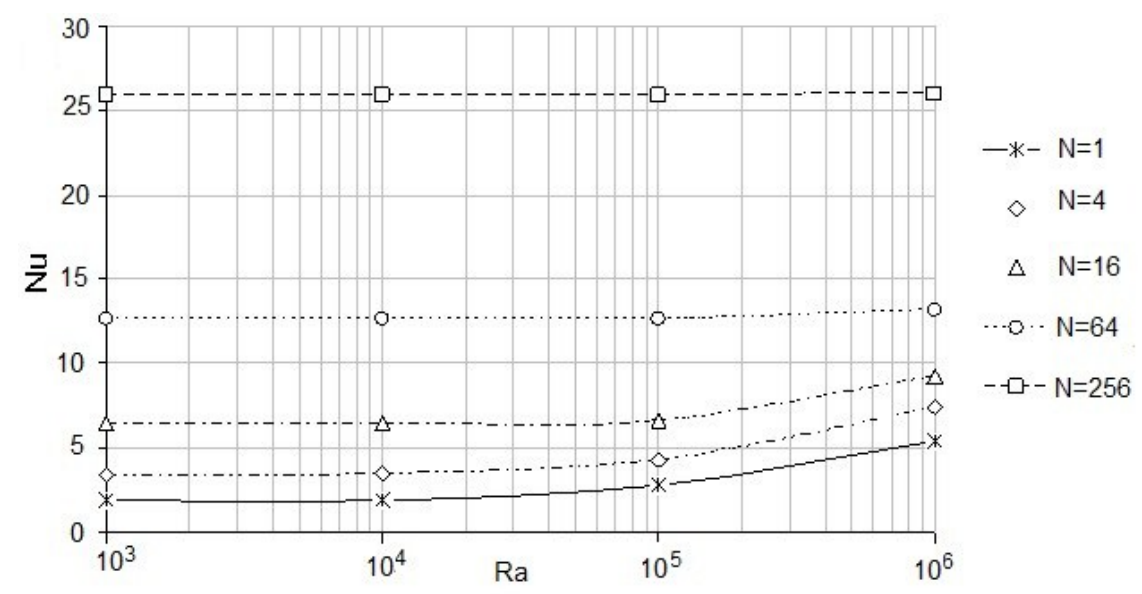

Fig. 4: Nusselt variations for the enclosure with different numbers of heating blocks.
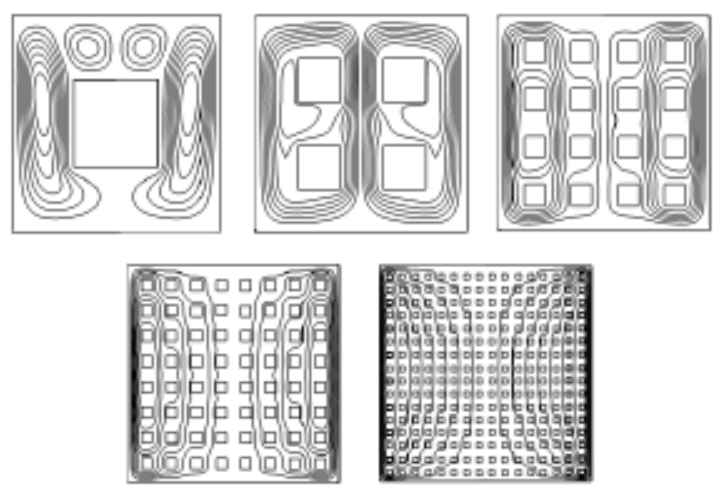

(a)
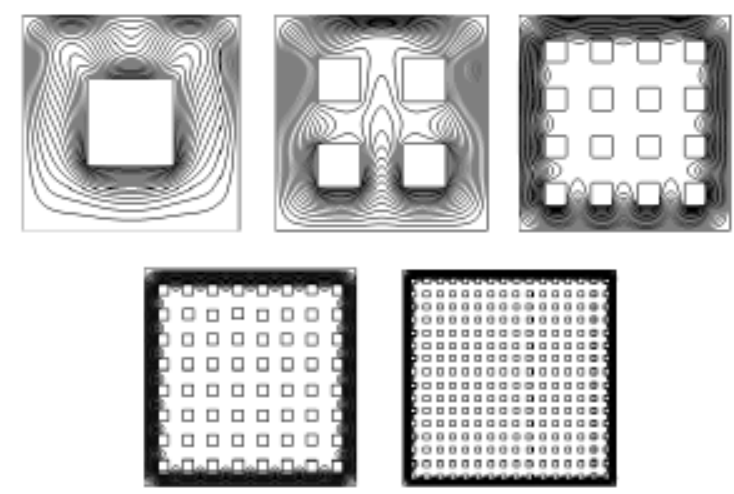

(b)

Fig. 5: The enclosure with $N=1,4,16,64,256$ heating blocks and $R a=10^{5}$.

a) Stream lines, b) Isotherms.

There is also another effective factor in increasing the enclosure heat transfer that by minifying solid phase heating and nearing them to enclosures' walls, its role will be highlighted. By observing the isothermal lines in Fig. 5b for the enclosure with different numbers of heating blocks, the severe condensing of Isothermal lines near the enclosures' walls can be seen. However, the fluid and heating blocks in an extended area in the middle of the enclosure have the same temperature. These indicate the high transfer rate of conduction between the cold wall of the container and the heating components near the walls. In fact, the rate of heat transfer conduction will be increased for finer heating blocks and reducing their distance with walls, the conduction mechanism has allocated a large 
contribution of heat transfer of the whole container to itself. Increasing the Rayleigh number has a direct effect on the heat transfer rate. But, by increasing the number of heating blocks and distributing them across the entire enclosure, the rate of increase in heat transfer due to increased Rayleigh number is so decreased that it could be neglected. Observing the results presented in Table 4 and the related curves in Fig. 5, this fact will be recognized. As stated earlier, according to stream lines and isotherms, by increasing the number of heating blocks and subsequently approaching some of them to the enclosure walls, the role of the conduction mechanism in heat transfer is more pronounced compared to that of the convection mechanism. So, the convection intensity and fluid rotating flow variations have little effect on the rate of the enclosure heat transfer. Accordingly, variation in Rayleigh number, with a direct impact on buoyancy force and fluid flow in the enclosure, will not have significant effect on the rate of heat transfer in an enclosure with a lot of heating blocks.

\subsection{Porous Media Model}

In this section, wuth the help of computer code and a trend like that in the previous section, the natural convection in porous media will be analyzed. As noted earlier, recently, a similar investigation in [15] was done in specified conditions. So, here, the results of the computer code is compared to that of the mentioned reference, and thereafter making sure about its proper performance in modelling the porous media. The effect of the variation in average Rayleigh number of this media $\left(R a_{m}\right)$ on heat transfer rate that is not investigated in that reference will be studied. In this regard, a squared enclosure with insulated horizontal and vertical walls at two different temperatures containing some parts of solid phase is considered, as seen in Fig. 6. The arrangement of solid blocks in the enclosure is like that in the previous section but in the model of porous media the distance between the enclosure walls and their adjacent blocks is half of the distance between the blocks. Dimensions of solid blocks in each case is determined in a way that the porosity is $\Phi=0.84$. The value of the average Nusselt of the hot wall is calculated for the number of blocks and Darcy numbers determined in Table 5, where $R a_{m}=10^{4}$ and $\operatorname{Pr}=1, k_{s} / \mathrm{k}_{\mathrm{f}}=1$. The obtained results in Table 5 are compared to that of similar references in [15].

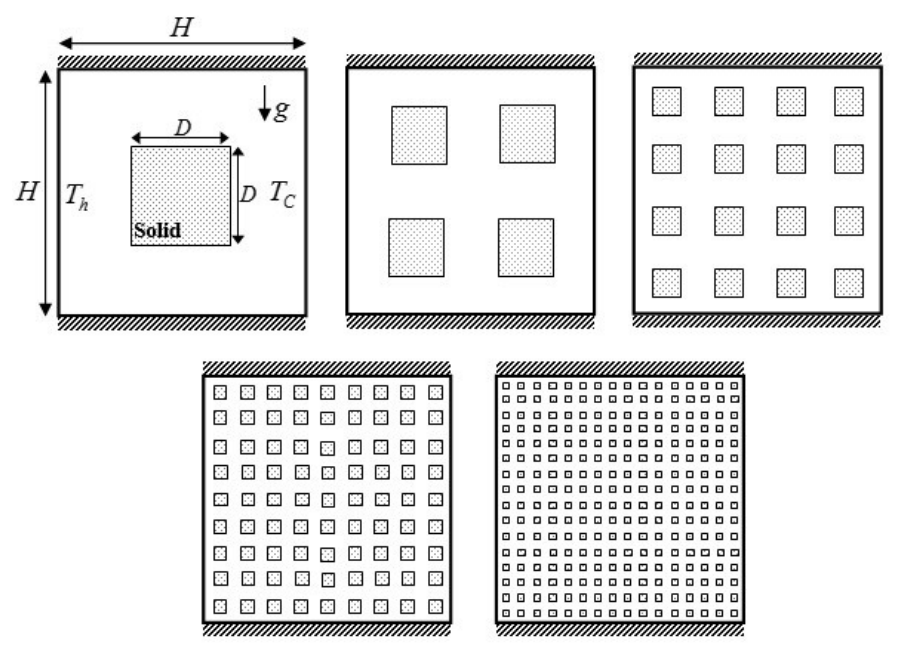

Fig. 6: A squared enclosure for porous media model. 
Table 5: Average Nusselt of porous medium for different Darcy numbers and $\operatorname{Pr}=1, \Phi=0.84$.

\begin{tabular}{ccccc}
\hline \multirow{2}{*}{$\boldsymbol{N}$} & $\boldsymbol{D a}$ & \multicolumn{2}{c}{ Braga and de Lemos [15] } & \\
\cline { 3 - 4 } & & Porous model & $\begin{array}{c}\text { Experimental } \\
\text { equations }\end{array}$ & \\
\hline 1 & $3.087 \mathrm{E}-02$ & 6.525 & 5.596 & 6.519 \\
4 & $7.717 \mathrm{E}-03$ & 9.620 & 7.848 & 9.595 \\
16 & $1.929 \mathrm{E}-03$ & 13.728 & 10.491 & 13.641 \\
64 & $4.823 \mathrm{E}-04$ & 19.482 & 13.820 & 19.389 \\
256 & $1.206 \mathrm{E}-04$ & 28.209 & 17.446 & 25.125 \\
\hline
\end{tabular}

According to the results of the above table, it seems that the supposed model can be a good approximation for porous media. Now, the effect of $R a_{m}=R a . D a$ on the rate of heat transfer from porous media will be investigated using the above model. In this regard, the heat transfer is obtained by the porous media model with $\Phi=0.84$ for different Darcy numbers (each representing a media with special permeability) where $R a_{m}=10^{2}, 10^{3}, 10^{4}$, $10^{5}$ and $P r=0.71, k_{s} / k_{f}=1$. The obtained results are shown in the Table 6 . As indicated in the results, the value of Nusselt has been increased by increasing average Rayleigh number. Noticing the related curves in the Fig. 7, is seen that for lower Darcy numbers (more blocks), rate of increase in Nusselt number by increasing average Rayleigh is higher.

Table 6: Average Nusselt of porous media for different Darcy numbers.

\begin{tabular}{|c|c|c|c|c|c|}
\hline \multirow{2}{*}{$N$} & \multirow{2}{*}{$D a$} & \multicolumn{4}{|c|}{$R a_{m}$} \\
\hline & & $10^{2}$ & $10^{3}$ & $10^{4}$ & $10^{5}$ \\
\hline 1 & $1.206 \mathrm{E}-04$ & 2.132 & 6.840 & 22.025 & 51.990 \\
\hline 4 & $4.823 \mathrm{E}-04$ & 1.843 & 5.938 & 19.332 & 36.316 \\
\hline 16 & $1.929 \mathrm{E}-03$ & 1.507 & 5.477 & 13.613 & 25.682 \\
\hline 64 & 7.717E-03 & 1.296 & 4.344 & 9.580 & 17.976 \\
\hline 256 & $3.087 \mathrm{E}-02$ & 1.277 & 3.200 & 6.513 & 12.405 \\
\hline
\end{tabular}



Fig. 7: Variations in Nusselt of porous media with different numbers of heating blocks. 
To determine the effect of the permeability of porous media on the rate of heat transfer, the curve of Nusselt's variations according to increase in Darcy number is depicted in Fig. 8. As said earlier, Darcy number is defined as $D a=K / H^{2}$ where $K$ is the permeability of porous media. In fact, the Darcy number is an indicator of the permeability of porous media.

As can be seen in Fig. 8, by increasing the Darcy Number, the rate of heat transfer from porous media has been decreased. Because a large part of heat transfer is done by conduction in porous media, although the increase in permeability will increase convection heat transfer, it has negative effect on the conductive heat transfer and accordingly on total heat transfer. It seems that in low Rayleigh numbers, a decrease in conductive heat transfer compares with increase in convection heat transfer due to an increase in permeability is in a range where at last the sum of the total heat transfer by increasing the Darcy number will remain almost constant. The variations in stream lines and isotherms related to different Darcy numbers due to change in the average Nusselt could be seen in Figs. 9-13. Because $k_{s} / k_{f}=1$ is considered, isotherms at solid-fluid boundary have not experienced slope changes. By comparing Figs. 9-13, it is seen that in the media with low Darcy number, stream lines and isotherms near the constant temperature walls specially in high average Rayleigh numbers will be more compacted that indicates increasing heat transfer rate due to more fluid flow near the walls. According to $R a_{m}=R a D a$, it could be said that in the enclosure with different solid blocks where the Darcy number is specified, increase in average Rayleigh indicates increase in Rayleigh number. As shown in Figs. 9-13, by increasing average Rayleigh the rotational flow inside the enclosure is more significant and the isotherms near the constant temperature walls will be very dense that indicates an increase in the heat transfer rate.



Fig. 8: Variations in Nusselt of porous media for different average Rayleigh numbers. 




Fig. 9: Stream lines (right) and isotherms (left) of the model of porous media with $D a=3.087 \times 10^{-2}$ and $\operatorname{Pr}=1, \Phi=0.84, k_{s} / k_{f}=1$.



Fig. 10: Stream lines (right) and isotherms (left) of the model of porous media with $D a=7.717 \times 10^{-3}$ and $P r=1, \Phi=0.84, k_{s} / k_{f}=1$. 


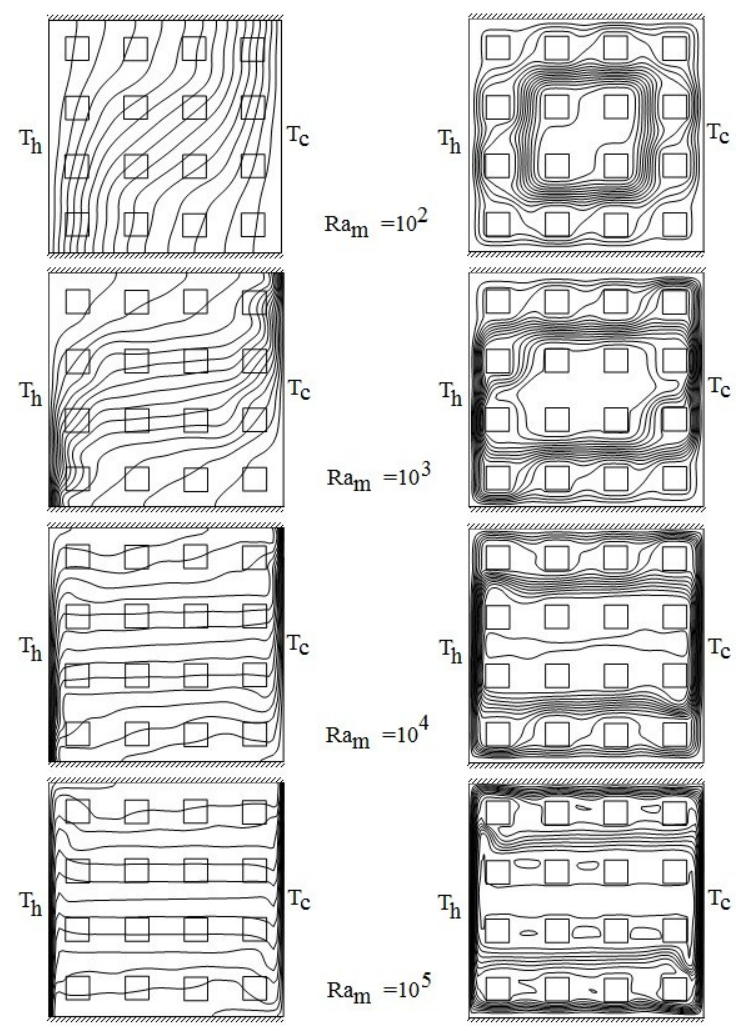

Fig. 11: Stream lines (right) and isotherms (left) of the model of porous media with $D a=1.929 \times 10^{-3}$ and $P r=1, \Phi=0.84, k_{s} / k_{f}=1$.

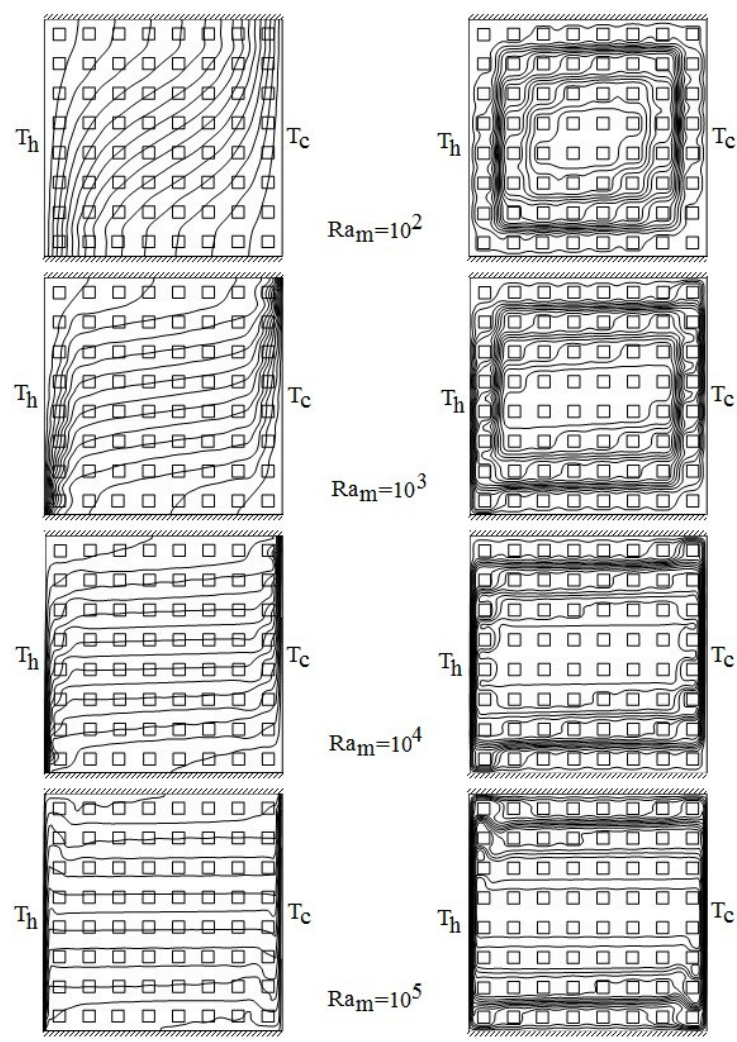

Fig. 12: Stream lines (right) and isotherms (left) of the model of porous media with $D a=4.823 \times 10^{-4}$ and $\operatorname{Pr}=1, \Phi=0.84, k_{s} / k_{f}=1$. 


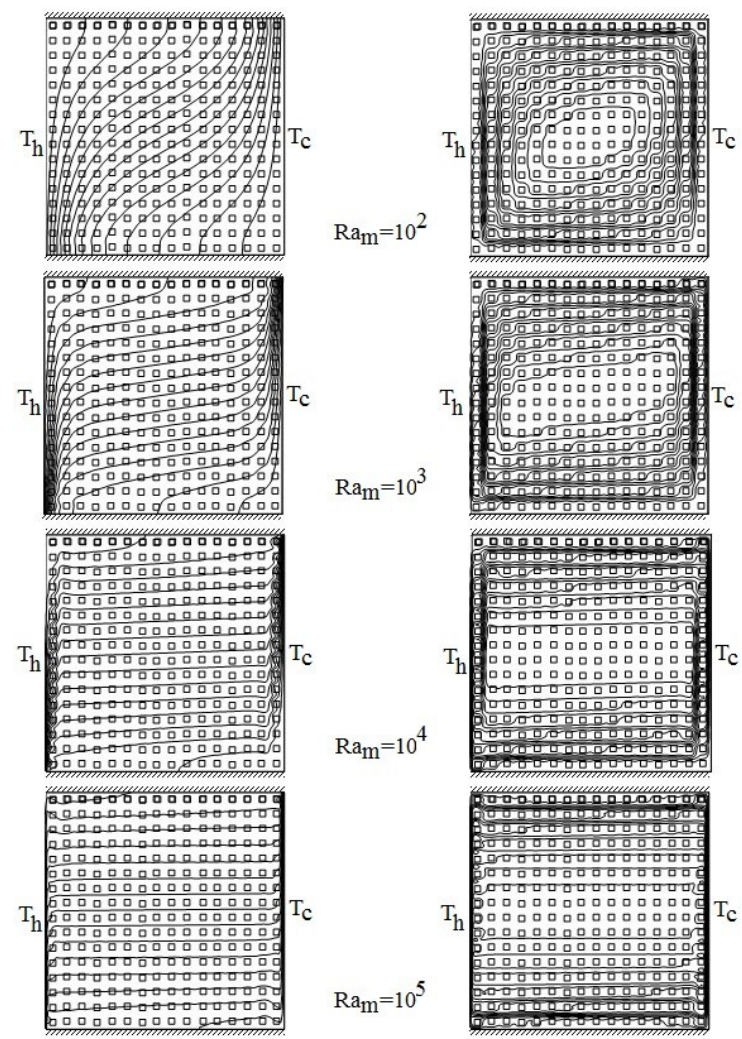

Fig. 13: Stream lines (right) and isotherms (left) of the model of porous media with $D a=1.206 \times 10^{-4}$ and $\operatorname{Pr}=1, \Phi=0.84, k_{s} / k_{f}=1$.

\section{CONCLUSION}

Based on the investigations done in this work, the following conclusions can be inferred.

- In designing electronic equipment, where sometimes high amounts of heat are produced by small parts, these parts should not be centralized in one region or arranged vertically or horizontally near each other, and as possible the heating blocks must be located in lower and colder parts of the equipment.

- In traditional warehouses, the products which the heat is damaging to them must be distributed uniformly across the entire available space and they should not be put on each other or in high places.

\section{REFERENCES}

[1] Alam P, Kumar A, Kapoor S, Ansari SR. (2012) Numerical investigation of natural convection in a rectangular enclosure due to partial heating and cooling at vertical walls. Communications in Nonlinear Science and Numerical Simulation, 17(6):2403-2414.

[2] Deng QH. (2008) Fluid flow and heat transfer characteristics of natural convection in square cavities due to discrete source-sink pairs. International Journal of Heat and Mass Transfer, 51(25-26):5949-5957.

[3] Ghernaout B, Bouabdallah S, Benchatti A, Bessaih R. (2014) Effect of buoyancy ratio on oscillatory double-diffusive convection in binary mixture. Numerical heat transfer, Part A: Applications, 66(8):928-946. 
[4] Bouabdallah S, Bessaih R, Ghernaout B, Benchatti A. (2011) Effect of an external magnetic field on the 3-D oscillatory natural convection of molten gallium during phase change. Numerical heat transfer, Part A: Applications, 60(1):84-105.

[5] Corcione M. (2003) Effects of the thermal boundary conditions at the sidewalls upon natural convection in rectangular enclosures heated from bellow and cooled from above. International Journal of Thermal Sciences, 42(2):199-208.

[6] Fasogbon PF. (2010) Analytical studies of heat and mass transfer by free convection in two dimensional irregular channel. Int. J. of Appl. Math. and Mech, 6(1):17-37.

[7] Calcagni B, Marsili F, Paroncini M. (2005) Natural convective heat transfer in square enclosures heated from below. Applied Thermal Engineering, 25(16):2522-2531.

[8] Aydin O, Yang WJ. (2000) Natural convection in enclosures with localized heating from below and symmetrical cooling from sides. International Journal of Numerical Methods for Heat \& Fluid Flow, 10(5):518-529.

[9] Merrikh AA. (2001) Blockage effects in natural convection in differentially heated enclosures. Jourbal of Enhanced Heat Transfer, 8(1):55-72.

[10] Merrikh AA, Lage JL, Mohamad AA. (2001) in: Chen Z, Erwin R (Eds.), Comparison between Pore-Level and Porous Medium Models for Natural Convection in a NonHomogeneous Enclosure. Fluid Flow and Transport in Porous Media: Mathematical and Numerical Treatment, Contemporary Mathematics, 295(32):387-396.

[11] Massarotti N, Nithiarasu P, Carotenuto A. (2003) Microscopic and macroscopic approach for natural convection in enclosures filled with fluid saturated porous medium. International Journal of Numerical Methods for Heat \& Fluid Flow, 13(7):862-886.

[12] Sezai I, Mohamad AA. (2000) Natural convection from a discrete heat source on the bottom of a horizontal enclosure. International Journal of Heat and Mass Transfer, 43(13):22572266.

[13] Merrikh AA, Lage JL. (2005) Natural convection in an enclosure with disconnected and conducting solid blocks. International Journal of Heat and Mass Transfer ,48(7):1361-1372.

[14] Braga EJ, de Lemos MJS. (2005) laminar natural convection in cavities filled with circular and square rods. International Communications in Heat and Mass Transfer, 32(10):12891297.

[15] Braga EJ, de Lemos MJS. (2005) Heat transfer in enclosures having a fixed amount of solid material simulated with heterogeneous and homogeneous models. International Journal of Heat and Mass Transfer, 48(23-24):4748-4765.

[16] Incropera FP, DeWitt DP, Bergman TL, Lavine AS. (2011) Introduction to Heat Transfer, 7th Ed.

[17] Bejan A, Kraus A. (2003) Heat Transfer Handbook, USA.

[18] De Vahl Davis G. (1983) Natural convection in a square cavity: A benchmark numerical solution. International Journal for Numerical Methods in Fluids, 3(3):249-264.

[19] House JM, Beckermann C, Smith TF. Effect of a centered conducting body on natural heat transfer in an enclosure. Numerical Heat Transfer, Part A: Applications, 18(2):213-225.

[20] Kalita JC, Dalal DC, Dass AK. (2001) Fully compact higher order computation of steady state natural convection in a square cavity. Physical Review, E64(066703):1-13.

[21] Merrikh AA, Lage JL. (2004) Effect of distributing a fixed amount of solid constituent inside a porous medium enclosure on the heat transfer process. Proceedings of International Conference on Applications of Porous Media(ICAPM):51-58, Évora, Portugal. 


\section{NOMENCLATURE}

$H \quad$ Height of the enclosure in x-direction m

D Width of the enclosure in y-direction $\mathrm{m}$

$T$ Temperature ${ }^{\circ} \mathrm{C}$

$T_{h} \quad$ Hot Temperature $\quad{ }^{\circ} \mathrm{C}$

$T_{c} \quad$ Cold Temperature $\quad{ }^{\circ} \mathrm{C}$

$P$ Pressure N.m ${ }^{-1}$

$X, Y \quad$ Cartesian coordinates -

$U, V \quad$ Cartesian velocities -

$C p \quad$ Specific heat capacity at constant pressure $\quad \mathrm{J} / \mathrm{kg} . \mathrm{k}$

$K \quad$ Thermal conductivity W/m.k

$g$ Acceleration of gravity $\mathrm{m} / \mathrm{s}^{2}$

i) Greek Symbols

$\begin{array}{clc}v & \text { Kinematic viscosity } & \mathrm{m}^{2} \cdot \mathrm{s}^{-1} \\ \rho & \text { Density } & \mathrm{kg} / \mathrm{m}^{3} \\ \beta & \text { Coefficient of thermal expansion at constant } & \mathrm{K}^{-1} \\ & \text { pressure } & \mathrm{kg} / \mathrm{m} \cdot \mathrm{s} \\ \mu & \text { Dynamic viscosity } & \mathrm{m}^{2} \cdot \mathrm{s}^{-1}\end{array}$

ii) Dimensionless Numbers

$R a \quad$ Rayleigh number, $\left(=g \beta\left(T_{h}-T_{c}\right) H^{3} / v \alpha\right)$

$\mathrm{Nu} \quad$ Local Nusselt number, $\left(=h_{\text {conv }} H / k\right)$

$N u_{m} \quad$ Average Nusselt number, $\left(=\int N u d A\right)$

$\operatorname{Pr} \quad$ Prandtl number, $(=v / \alpha)$

Da Darcy number, $(=K / H)$ 